Research Article

\title{
Emerging resistance of higher antimicrobials and growing sensitivity of old antimicrobials against existing infections in burns
}

\author{
Ajay Lunawat*, Rajesh Sharma, Venkatesh Kolla, Shailendra Patel
}

Department of of general surgery, SAIMS \& PGI, Indore, Madhya Pradesh, India

Received: 23 June 2015

Revised: 29 June 2015

Accepted: 13 July 2015

\section{*Correspondence:}

Dr. Ajay Lunawat,

E-mail: drajay_lunawat@rediffmail.com

Copyright: () the author(s), publisher and licensee Medip Academy. This is an open-access article distributed under the terms of the Creative Commons Attribution Non-Commercial License, which permits unrestricted non-commercial use, distribution, and reproduction in any medium, provided the original work is properly cited.

\begin{abstract}
Background: The widespread resistance of microorganisms to antibiotics threatens to be a future medical disaster. Antimicrobial resistance among a wide variety of human bacterial and fungal burn wound pathogens, particularly nosocomial isolates, limits the available therapeutic options for effective treatment of burn wound infections Objective: To analyze the emergence of resistance to higher group of antibiotics and shift of sensitivity towards older group of antibiotics.

Methods: The microbial colonization of wounds was studied from day of admission to date of discharge or date of expiry (2011-2014). The sampling included swabs taken from clinically deep areas of burn wounds prior to cleaning. Culture and sensitivity reports of urine, central line, bronchoscopic suction, catheter tips were not included in samples. Tissue biopsy during excision was included in the samples. Analysis done with the help of Chi-square test.

Results: Initially after burn injury there is predominance of staphylococcal group followed by gram negative organism, after which there is a predominance of gram negative organism. In this study we observed an increase in resistance to higher group of antibiotics like imipenem $(p>0.005)$ and increased susceptibility to polymyxin group of drugs $(\mathrm{p}<0.005)$.

Conclusions: It suggests that prevention is better than cure. Developing resistance can be prevented by misuse of antibiotics, premature change of antibiotics and prevention of cross contamination. For effective prevention of developing resistance to higher antibiotics the burn centres should look in and bring a strict antibiotic policy.
\end{abstract}

Keywords: Emerging resistance, Pseudomonas, MRSA, Polymyxin group

\section{INTRODUCTION}

The widespread resistance of microorganisms to antibiotics threatens to be a future medical disaster. ${ }^{1,2}$ Antimicrobial resistance among a wide variety of human bacterial and fungal burn wound pathogens, particularly nosocomial isolates, limits the available therapeutic options for effective treatment of burn wound infections. ${ }^{3-6}$ MRSA, methicillin-resistant coagulasenegative Staphylococci, vancomycin-resistant Enterococci, and multiple resistant Gram-negative bacteria that possess several types of beta-lactamases, including extended spectrum beta-lactamases (ESBL), ampC-betalactamases, and metallobeta-lactamases (MBL), have been emerging as serious pathogens in hospitalized patients. ${ }^{7,8}$ Gram positive organisms are initially prevalent during hospital stay; then gradually become superseded by gram negative opportunists that appear to have a greater propensity to invade. Pseudomonas aeruginosa is one such difficult-to-treat organism, and reports from the National Nosocomial Infections Surveillance (NNIS) in 1998 indicated that it 
then ranked second among the most commonly isolated Gram-negative pathogens.9-11 Multi-resistance in other Gram-negative bacteria, including strains resistant to carbapenems, is also emerging as a global health issue. $^{12,13}$ Outbreaks of P. aeruginosa resistant to most available beta-lactams, aminoglycosides and fluoroquinolones have been reported among cysticfibrosis patients, as well as in burns units and cancer centres. ${ }^{14-17}$

Now clinical isolates with mutational fluoroquinolone resistance and metallo-lactamases are being seen with increasing frequency worldwide. ${ }^{18}$ Colistin, also known as polymyxin $\mathrm{E}$, is an old antibiotic with significant in vitro activity against some multiresistant Gram-negative pathogens, including P. aeruginosa, A. baumannii and Klebsiella pneumoniae. When the use of a beta-lactam, aminoglycoside, or quinolone is ineffective, the polymyxins, particularly colistin, remain drugs of last resort. ${ }^{19}$

Objective: To analyze the emergence of resistance to higher group of antibiotics and shift of sensitivity towards older group of antibiotics.

\section{Inclusion criteria}

Patient admitted within 24 hours of burn injury.

\section{Exclusion criteria}

a) Patient admitted after 24 hours or referred from other hospital.

b) Patient under the age of 18 years and greater than $70 \%$ of total burn surface area.

\section{METHODS}

The microbial colonization of wounds was studied from day of admission to date of discharge or death (20112014). The sampling included swabs taken from clinically deep areas of burn wounds prior to cleaning. Later, swabs were taken on debridement or excision and grafting. The swabs from burn wounds were taken on day zero, 3, 5, 7 and then twice a week till patients are discharged or succumb to burn injuries. Culture and sensitivity reports of urine, central line, bronchoscopic suction, catheter tips were not included in samples. Tissue biopsy during excision was included in the samples. Various culture media are used, e.g. MacConkey agar, blood agar, etc. After incubation for 18-48 h, sensitivity tests performed. Analysis done with the help of Chi-square test.

\section{RESULTS}

A total number of 1665 samples of swab were taken of which 615 samples are taken during first five days, and out of 615 samples 305 (49.6\%) turned out to be sterile. over remaining 315 samples Staphylococcus aureus was the commonest micro-organism $(13.5 \%)$, of which MRSA strains of Staphylococcus constitutes (6.5\%), Pseudomonas (9.8\%), Klebsiella (7.9\%), E. coli $(6.5 \%)$ were other strains grown and separated during first week.

Table 1: Microorganism organism isolated during first 5 days.

\begin{tabular}{|lll|}
\hline Microbe & Samples & $\%$ \\
\hline Staphylococcus aureus & 83 & $13.5 \%$ \\
\hline Pseudomonas aeruginosa & 60 & $9.8 \%$ \\
\hline Klebsiella species & 49 & $7.9 \%$ \\
\hline E. coli & 40 & $6.5 \%$ \\
\hline Staphylococcus aureus (MRSA) & 40 & $6.5 \%$ \\
\hline Acinetobacter baumanni & 23 & $3.7 \%$ \\
\hline Proteus sp. & 15 & $2.5 \%$ \\
\hline No growth & 305 & $49.6 \%$ \\
\hline
\end{tabular}

Out of remaining 1050 samples which were taken from the burn wounds, after 5 days bacterial isolates were found in $1042(99.2 \%)$ samples and only 8 wound swabs were sterile $(0.8 \%)$, pseudomonas was leading $(38.9 \%)$ followed by Klebsiella (26.9\%), MRSA (11.6\%) Staphylococcus aureus (6.8\%), E. coli (3.7\%) Proteus sp. $(5.9 \%)$, Acinetobacter $(2.8 \%)$.

Table 2: Microbial colonization after $5^{\text {th }}$ day.

\begin{tabular}{|lll|}
\hline Microbe & Samples & $\%$ \\
\hline Pseudomonas aeruginosa & 408 & $38.9 \%$ \\
\hline Klebsiella pneumonia & 282 & $26.9 \%$ \\
\hline Staphylococcus aureus (MRSA) & 122 & $11.6 \%$ \\
\hline Staphylococcus aureus & 71 & $6.8 \%$ \\
\hline E. coli & 39 & $3.7 \%$ \\
\hline Enterobacter sp. & 22 & $2.1 \%$ \\
\hline Proteus sp. & 62 & $5.9 \%$ \\
\hline Acinetobacter baumanni & 30 & $2.8 \%$ \\
\hline Streptococcus sp. & 6 & $0.5 \%$ \\
\hline No growth & 8 & $0.8 \%$ \\
\hline
\end{tabular}

\section{Pattern of antibiotic sensitivity}

Among gram positive organism Staphylococcus aureus is $84 \%$ sensitive to chloramphenicol, $88.56 \%$ sensitive to rifampicin, $99.5 \%$ sensitive to vancomycin and $98.7 \%$ sensitive to linezolid and marked resistance is observed for penicillin groups and increased resistance pattern is observed for clindamycin (Table 4).

Among gram negative organism, pseudomonas is most common followed by Klebsiella, E. coli, Proteus and Acinetobacter baumanni.

Pseudomonas was markedly resistant to penicillins (96\%) piperacillin/tazobactum $(77.3 \%)$ whereas resistance was $52.4 \%$ for amikacin and $63.2 \%$ for gentamicin, ceftazidime $(92.6 \%)$ and tobramycin $(71.8 \%)$ (Table 3$)$. 
In this study, we observed an increase in resistance to the carbepenem group over a period from 2011 to 2014, in 2011 Pseudomonas is $85 \%$ sensitive to the imipinem which gradually reduced to $60 \%$ by the end of 2014 , and in other Gram negative group there is an average of $10 \%$ reduction in sensitivity to carbepenem group. During this period we observed an increased sensitivity to the polymyxin group of drugs (90\%) (Table $5 \& 6$ ).

Klebsiella pneumonia is $92 \%$ resistant to penicillin and cephalosporin group of drugs, $75 \%$ resistance to co trimoxazole group and shows $73 \%$ sensitivity to imipinem and $78 \%$ sensitivity to polymyxin group of drugs and $75 \%$ sensitivity to tetracycline drug. As observed over this study period there is increased resistance to imipinem and no change in sensitivity towards polymyxin group.

E. coli is shows similar resistant pattern to penicillin and cephalosporin group but there is also marked resistance observed towards aminoglycosides group of drugs (avg$75 \%$ ) and $77 \%$ sensitive to imipenem and $70 \%$ to polymyxin group of drugs. As observed over this study period there is increased resistance to imipenem and no change in sensitivity to polymyxin group.

Proteus and Acinetobacter shows similar sensitivity pattern to imipenem and colistin.

Table 3: Antimicrobial sensitivity pattern of gram negative organisms.

\begin{tabular}{|c|c|c|c|c|c|c|c|c|c|c|c|c|c|}
\hline \multirow[t]{2}{*}{$\begin{array}{l}\text { Antimicrobial } \\
\text { agent }\end{array}$} & \multirow[t]{2}{*}{ Sensitivity } & \multicolumn{2}{|c|}{$\begin{array}{l}\text { Pseudomonas } \\
\text { aeruginosa } \\
\text { N-468 }\end{array}$} & \multicolumn{2}{|c|}{$\begin{array}{l}\text { E.coli } \\
\text { N-79 }\end{array}$} & \multicolumn{2}{|c|}{$\begin{array}{l}\text { Klebsiella } \\
\text { N-331 }\end{array}$} & \multicolumn{2}{|c|}{$\begin{array}{l}\text { Proteus } \\
\text { N-77 }\end{array}$} & \multicolumn{2}{|c|}{$\begin{array}{l}\text { Enterobacter } \\
\text { N-22 }\end{array}$} & \multicolumn{2}{|c|}{$\begin{array}{l}\text { Acinetobacter } \\
\mathbf{N}-53\end{array}$} \\
\hline & & $\mathbf{N}$ & $\%$ & $\mathbf{N}$ & $\%$ & $\mathbf{N}$ & $\%$ & $\mathbf{N}$ & $\%$ & $\mathbf{N}$ & $\%$ & $\mathbf{N}$ & $\%$ \\
\hline \multirow{2}{*}{ AMP } & $\mathrm{S}$ & 17 & 3.6 & 12 & 15.1 & 25 & 7.5 & 0 & 0 & 1 & 5 & 0 & 0 \\
\hline & $\mathrm{R}$ & 451 & 96.4 & 67 & 84.9 & 306 & 92.5 & 77 & 100 & 21 & 95 & 53 & 100 \\
\hline \multirow{2}{*}{ AN } & $\mathrm{S}$ & 224 & 47.9 & 18 & 23 & 252 & 76.1 & 25 & 32.5 & 8 & 36.6 & 5 & 9.5 \\
\hline & $\mathrm{R}$ & 244 & 52.1 & 53 & 67 & 79 & 23.9 & 52 & 67.5 & 14 & 63.4 & 48 & 90.5 \\
\hline \multirow{2}{*}{ GN } & $\mathrm{S}$ & 172 & 36.7 & 10 & 12.7 & 251 & 75.8 & 13 & 16.9 & 4 & 18 & 5 & 9.5 \\
\hline & $\mathrm{R}$ & 296 & 63.3 & 69 & 87.3 & 80 & 24.2 & 64 & 83.1 & 18 & 82 & 48 & 90.5 \\
\hline \multirow{2}{*}{ CRO } & $\mathrm{S}$ & 0 & 0 & 0 & 0 & 14 & 4.2 & 7 & 9 & 0 & 0 & 0 & 0 \\
\hline & $\mathrm{R}$ & 468 & 100 & 79 & 100 & 317 & 95.8 & 5 & 91 & 22 & 100 & 53 & 100 \\
\hline \multirow{2}{*}{ CAZ } & $\mathrm{S}$ & 23 & 5 & 2 & 2.4 & 15 & 4.5 & 5 & 6.4 & 1 & 5 & 0 & 0 \\
\hline & $\mathrm{R}$ & 445 & 95 & 77 & 97.6 & 316 & 93.5 & 72 & 93.6 & 21 & 95 & 53 & 100 \\
\hline \multirow{2}{*}{ SXT } & $\mathrm{S}$ & 32 & 6.8 & 12 & 15.4 & 79 & 23.8 & 0 & 0 & 0 & 0 & 0 & 0 \\
\hline & $\mathrm{R}$ & 436 & 93.2 & 57 & 84.6 & 252 & 76.2 & 77 & 100 & 22 & 100 & 53 & 100 \\
\hline \multirow{2}{*}{ TBN } & $\mathrm{S}$ & 128 & 27.4 & 19 & 24 & 70 & 21.2 & 14 & 18.1 & 2 & 6 & 0 & 0 \\
\hline & $\mathrm{R}$ & 340 & 72.6 & 50 & 76 & 261 & 79.8 & 62 & 81.9 & 20 & 94 & 53 & 100 \\
\hline \multirow{2}{*}{ PIP/TZ } & $\mathrm{S}$ & 107 & 22.9 & 0 & 0 & 49 & 14.8 & 1 & 1.3 & 2 & 6 & 1 & 1.9 \\
\hline & $\mathrm{R}$ & 361 & 77.1 & 79 & 100 & 282 & 95.2 & 76 & 98.7 & 20 & 94 & 52 & 98.1 \\
\hline \multirow{2}{*}{ CIP } & $\mathrm{S}$ & 230 & 48.6 & 22 & 27.8 & 107 & 32.3 & 34 & 44.1 & 4 & 18 & 0 & 0 \\
\hline & $\mathrm{R}$ & 241 & 51.4 & 49 & 72.2 & 224 & 67.7 & 42 & 56.9 & 18 & 82 & 55 & 100 \\
\hline \multirow{2}{*}{ IPM } & $\mathrm{S}$ & 349 & 74.6 & 61 & 77 & 242 & 73.1 & 60 & 77.9 & 16 & 72.8 & 29 & 52.7 \\
\hline & $\mathrm{R}$ & 119 & 25.4 & 18 & 23 & 89 & 26.9 & 17 & 22.1 & 6 & 28.2 & 26 & 47.3 \\
\hline \multirow{2}{*}{$\mathrm{C}$} & $\mathrm{S}$ & 113 & 24.2 & 28 & 35.4 & 110 & 33.2 & 23 & 29.8 & 10 & 45.5 & 16 & 31.2 \\
\hline & $\mathrm{R}$ & 355 & 75.8 & 51 & 64.6 & 221 & 66.8 & 54 & 70.1 & 12 & 54.5 & 37 & 69.8 \\
\hline \multirow{3}{*}{ PMB } & $\mathrm{S}$ & 369 & 78.4 & 0 & 0 & 259 & 78.2 & 0 & 0 & 0 & 0 & 1 & 1.9 \\
\hline & $\mathrm{R}$ & 92 & 21.2 & 79 & 100 & 72 & 21.8 & 77 & 100 & 22 & 100 & 52 & 98.1 \\
\hline & & $\mathrm{n}-268$ & $\%$ & $\mathrm{n}-50$ & $\%$ & $\mathrm{n}-220$ & $\%$ & $\mathrm{n}-54$ & $\%$ & $\mathrm{n}-12$ & $\%$ & $\mathrm{n}-50$ & \\
\hline \multirow{2}{*}{$\mathrm{COL}$} & $\mathrm{S}$ & 218 & 81.4 & 35 & 70 & 174 & 79 & 29 & 53.7 & 8 & 67.7 & 47 & 94 \\
\hline & $\mathrm{R}$ & 50 & 18.6 & 15 & 30 & 46 & 21 & 25 & 47.3 & 4 & 22.3 & 3 & 6 \\
\hline
\end{tabular}

AMP-Amoxy, AN-Amikacin, GN-Gentamicin, CRO-Ceftriaxone, CAZ-Ceftazidime,

TBN-Tobramycin, PIP/TZ-Piperacillintazobactum, CIP-Ciprofloxacin, IPM-Imipinem,

C-Chloramphenicol, PMB-Polymyxinb, COL-Colistin, SXT-Co-Trimoxazole 
Table 4: Antimicrobial sensitivity of gram positive organism.

\begin{tabular}{|c|c|c|c|c|c|}
\hline \multirow{2}{*}{$\begin{array}{l}\text { Antimicrobial } \\
\text { agent }\end{array}$} & \multirow{2}{*}{ Sensitivity } & \multicolumn{2}{|c|}{$\begin{array}{l}\text { Staphylococcus } \\
\text { aureus (N-235) }\end{array}$} & \multicolumn{2}{|c|}{ CoNS (N-49) } \\
\hline & & $\mathbf{N}$ & $\%$ & $\mathbf{N}$ & $\%$ \\
\hline \multirow[b]{2}{*}{$\mathrm{P}$} & $\mathrm{S}$ & 15 & 6.4 & 6 & 12 \\
\hline & $\mathrm{R}$ & 220 & 93.6 & 43 & 88 \\
\hline \multirow{2}{*}{ AMXY/SUL } & $\mathrm{S}$ & 106 & 45.1 & 12 & 41 \\
\hline & $\mathrm{R}$ & 229 & 54.9 & 17 & 59 \\
\hline \multirow{2}{*}{ CRO } & $\mathrm{S}$ & 35 & 14.9 & 7 & 14.2 \\
\hline & $\mathrm{R}$ & 200 & 85.1 & 42 & 85.8 \\
\hline \multirow{2}{*}{$\mathrm{O}$} & $\mathrm{S}$ & 35 & 20 & 8 & 16.3 \\
\hline & $\mathrm{R}$ & 137 & 80 & 41 & 83.7 \\
\hline \multirow{2}{*}{$\mathrm{L}$} & S & 96 & 40 & 17 & 34.6 \\
\hline & $\mathrm{R}$ & 149 & 60 & 32 & 65.4 \\
\hline \multirow{2}{*}{ SXT } & S & 56 & 23.8 & 8 & 16.3 \\
\hline & $\mathrm{R}$ & 179 & 76.2 & 41 & 83.7 \\
\hline \multirow{2}{*}{$\mathrm{R}$} & S & 207 & 88 & 46 & 93.8 \\
\hline & $\mathrm{R}$ & 28 & 12 & 3 & 6.2 \\
\hline \multirow{2}{*}{$\mathrm{T}$} & $\mathrm{S}$ & 178 & 75.7 & 42 & 85.7 \\
\hline & $\mathrm{R}$ & 67 & 24.3 & 7 & 14.3 \\
\hline \multirow{2}{*}{$\mathrm{C}$} & S & 195 & 84.2 & 43 & 87.8 \\
\hline & $\mathrm{R}$ & 40 & 5.8 & 7 & 12.2 \\
\hline \multirow{2}{*}{ CLN } & $\mathrm{S}$ & 167 & 71 & 33 & 67.3 \\
\hline & $\mathrm{R}$ & 68 & 29 & 16 & 32.7 \\
\hline \multirow{2}{*}{ LNZ } & $\mathrm{S}$ & 232 & 98.7 & 47 & 96 \\
\hline & $\mathrm{R}$ & 3 & 1.3 & 2 & 4 \\
\hline \multirow{2}{*}{ VA } & $\mathrm{S}$ & 234 & 99.5 & 47 & 96 \\
\hline & $\mathrm{R}$ & 1 & 0.7 & 2 & 4 \\
\hline
\end{tabular}

P-Penicillin, Amxy/Sul-Amoxycillin and Sulbactum, CRO-Ceftriaxone, O-Oxacillin, L-Levofloxacin, R-Rifampin, T-Tetracycline, C-Chloramphenicol, CLN-Clindamycin, Lnz-Linezolid,

VA-Vancomycin, SXT-Co-Trimoxazole, CoNS-Coagulase negative staphylococcus

Table 5: Changing pattern of antibiotic sensitivity for gram negative organism - Antibiotic sensitivity pattern during 2011-2012.

\begin{tabular}{|llllll|}
\hline $\begin{array}{l}\text { Antibiotics } \\
\text { sensitive }\end{array}$ & $\begin{array}{l}\text { Pseudomonas } \\
\text { aeruginosa } \\
\text { N-226 }\end{array}$ & $\begin{array}{l}\text { Klebsiella } \\
\text { pneumonia } \\
\text { N-178 }\end{array}$ & $\begin{array}{l}\text { E. coli } \\
\text { N-49 }\end{array}$ & $\begin{array}{l}\text { Proteus } \\
\text { N-40 }\end{array}$ & $\begin{array}{l}\text { Acinetobacter } \\
\text { N-24 }\end{array}$ \\
\hline AMP & $4.8 \%(n-11)$ & $11 \%(n-20)$ & $24.4 \%(n-11)$ & $7.5 \%(n-3)$ & 0 \\
\hline AN & $47.7 \%(n-108)$ & $78 \%(n-139)$ & $32.6 \%(n-16)$ & $32.5 \%(n-13)$ & $16.7 \%(n-4)$ \\
\hline GN & $45 \%(n-102)$ & $76.4 \%(n-136)$ & $2.6 \%(n-1)$ & $17.5 \%(n-7)$ & $16.7 \%(n-4)$ \\
\hline CAZ & $6 \%(n-14)$ & $9 \%(n-16)$ & 0 & $10 \%(n-4)$ & 0 \\
\hline TBN & $46 \%(n-104)$ & $19.7 \%(n-35)$ & $6.1 \%(n-3)$ & $22.5 \%(n-9)$ & 0 \\
\hline PIP/TZ & $25.2 \%(n-57)$ & $15.1 \%(n-27)$ & $14.2 \%(n-7)$ & $2.5 \%(n-1)$ & $4.1 \%(n-1)$ \\
\hline SXT & $14 \%(n-32)$ & $21 \%(n-38)$ & $10.2 \%(n-5)$ & 0 & 0 \\
\hline CIP & $53.9 \%(n-122)$ & $34.2 \%(n-61)$ & $30.6 \%(n-15)$ & $25 \%(n-10)$ & 0 \\
\hline IPM & $85 \%(n-192)$ & $78.1 \%(n-139)$ & $77.6 \%(n-38)$ & $77.5 \%(n-31)$ & $50 \%(n-12)$ \\
\hline PMB & $76 \%(n-172)$ & $78.1 \%(n-139)$ & $2.1 \%(n-1)$ & $2.5 \%(n-1)$ & $4.1 \%(n-1)$ \\
\hline T & - & $82.5 \%(n-147)$ & $57.1 \%(n-28)$ & - & - \\
\hline
\end{tabular}


Table 6: Changing pattern of antibiotic sensitivity for gram negative organism - Antibiotic sensitivity pattern during 2013-2014.

\begin{tabular}{|llllll|}
$\begin{array}{l}\text { Antibiotics } \\
\text { sensitive }\end{array}$ & $\begin{array}{l}\text { Pseudomonas } \\
\text { aeruginosa } \\
\text { N-242 }\end{array}$ & $\begin{array}{l}\text { Klebsiella } \\
\text { pneumonia } \\
\text { N-153 }\end{array}$ & $\begin{array}{l}\text { E.coli } \\
\text { N-30 }\end{array}$ & $\begin{array}{l}\text { Proteus } \\
\text { N-37 }\end{array}$ & $\begin{array}{l}\text { Acinetobacter } \\
\text { N-29 }\end{array}$ \\
\hline AMP & $2.9 \%(n-7)$ & $5.3 \%(n-8)$ & 0 & 0 & 0 \\
\hline AN & $47.5 \%(n-115)$ & $73.8 \%(n-113)$ & $33.3 \%(n-10)$ & $32.4 \%(n-12)$ & $3.4 \%(n-1)$ \\
\hline GN & $28.9 \%(n-70)$ & $75.8 \%(n-116)$ & $16.6 \%(n-10)$ & $16.2 \%(n-6)$ & $3.4 \%(n-1)$ \\
\hline CAZ & 0 & 0 & 0 & 0 & 0 \\
\hline TBN & $12.8 \%(n-31)$ & $44.5 \%(n-68)$ & $30 \%(n-9)$ & $16.2 \%(n-6)$ & 0 \\
\hline SXT & 0 & 0 & $20 \%(n-6)$ & $8.1 \%(n-3)$ & 0 \\
\hline PIP/TZ & $20.7 \%(n-50)$ & $15.7 \%(n-24)$ & $13.3 \%(n-4)$ & $8.1 \%(n-3)$ & $3.4 \%(n-1)$ \\
\hline CIP & $44.6 \%(n-108)$ & $30.7 \%(n-47)$ & $30 \%(n-9)$ & $14 \%(n-5)$ & 0 \\
\hline IPM & $59.1 \%(n-143)$ & $68 \%(n-104)$ & $70 \%(n-21)$ & $75.6 \%(n-28)$ & $55.7 \%(n-16)$ \\
\hline COL & $89.7 \%(n-217)$ & $79 \%(n-121)$ & $90 \%(n-27)$ & $81 \%(n-30)$ & $96.5 \%(n-28)$ \\
\hline T & - & $75 \%(n-115)$ & $50 \%(n-15)$ & - & - \\
\hline
\end{tabular}

Table 7: Year wise association of antibiotics with bacterial sensitivity.

\begin{tabular}{|lll|lllll|}
\hline \multirow{2}{*}{ AG } & & Pseudomonas & Klebsiella & E. coli & Proteus & Acinetobacter & P value \\
& $2011-12$ & 106 & 133 & 8 & 10 & 4 & 0.734 \\
\hline \multirow{2}{*}{ PIP/TZ } & $2013-14$ & 92 & 115 & 10 & 9 & 1 & \multirow{2}{*}{0.976} \\
& $2011-12$ & 57 & 27 & 7 & 1 & 1 & \\
\multirow{2}{*}{ IPM } & $2013-14$ & 50 & 24 & 4 & 3 & 1 & 0.393 \\
& $2011-12$ & 192 & 139 & 38 & 31 & 12 & \multirow{2}{*}{0.000} \\
\hline \multirow{2}{*}{ PMB/E } & $2011-12$ & 143 & 104 & 21 & 28 & 16 & 1 \\
\hline
\end{tabular}

*Chi-square test was applied

As there is already marked resistance for penicillins, cephalosporins, Co-trimoxazole and tetracycline group (other than E. coli and Klebsiella), we include the above antibiotics which showed increasing resistance pattern over a period of 2011-2014.

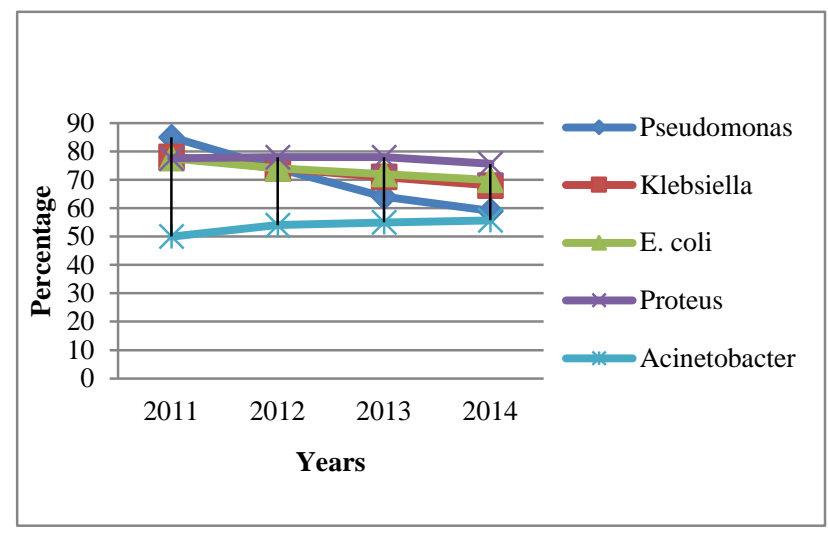

Figure 1: Changing trends of sensitivity of various bacterial isolates to imipinem.

Showing the bacterial sensitivity to imipinem. There is increased resistance observed for imipinem drug over four years for gram negative group of organisms.
From the above comparative Table 7 of year wise association of antibiotics with bacterial sensitivity and analysis done with the help of Chi-square test. It was observed that gram negative organisms are significantly susceptible to $(\mathrm{p}<0.005)$ polymyxin group of drugs and there has been a significant increase in resistance to imipinem, piperacillin and aminoglycosides ( $>00.005)$.

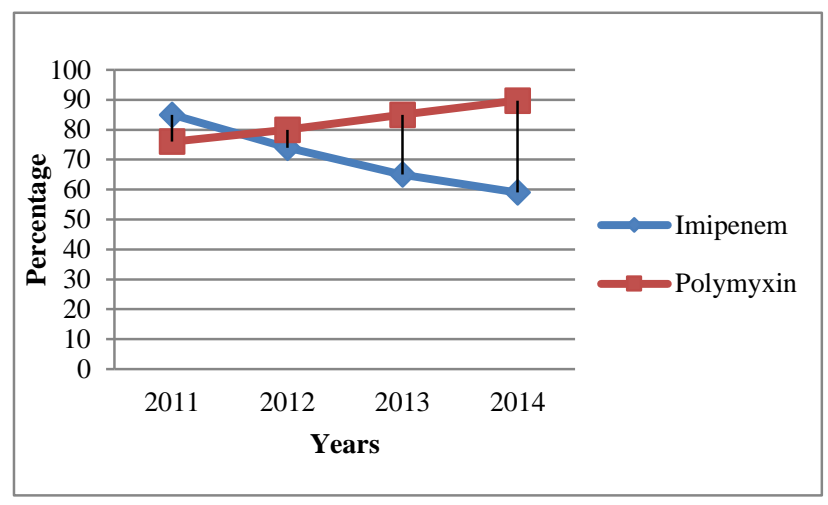

Figure 2: Showing changing trends of pseudomonas sensitivity to antimicrobials.

Shows decreased sensitivity of pseudomonas to impinem and increase sensitivity to polymyxin group of drugs. 


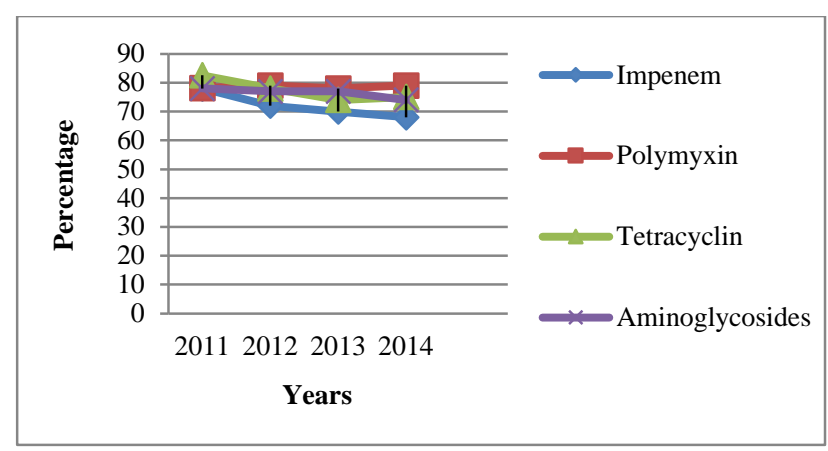

Figure 3: Changing trends of Klebsiella sensitivity to antimicrobials.

Shows changing trends of Klebsiella organism to various antibiotics, increasing resistance to imipinem, tetracycline and aminoglycoside and increasing sensitivity to polymyxin group.

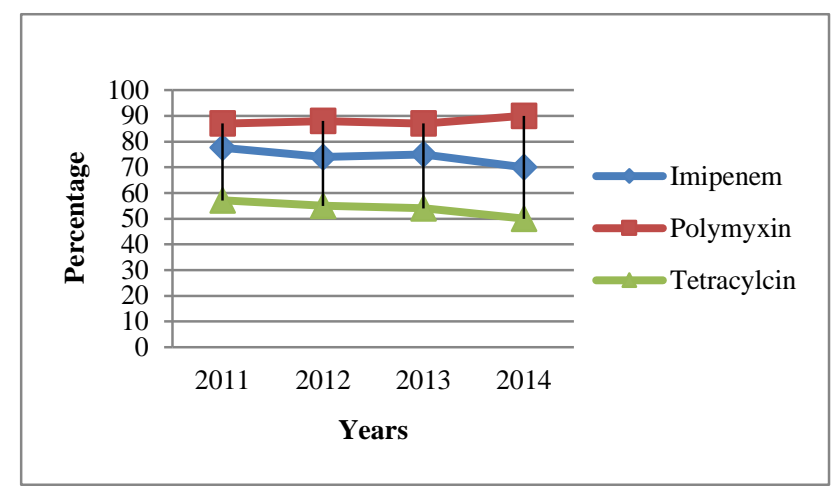

Figure 4: Changing trends of E. coli sensitivity to antimicrobials.

Shows increasing resistance to imipinem and tetracycline and increase in sensitivity to polymyxin group.

\section{DISCUSSION}

There is significant change in the antibiograms of the gram negative organism as when compared to the gram positive organisms. Most of the gram positive organisms belong to the MRSA group which are sensitive to the vancomycin, linezolid, rifampicin, chloramphenicol and clindamycin. There is some amount of increase in resistance observed to clindamycin group of drugs over this period. Various studies showed that staphylococcus is resistant to penicillin (97\%), clindamycin (77\%) tetracycline $(57 \%)$, rifampicin $(54 \%)$, chloramphenicol $(17 \%)$, linezolid $(10 \%)$ and vancomycin $(0 \%) .{ }^{20}$ But as compared to our study over this period there is similar resistant patterns with penicillin group but sensitivity to tetracycline (74\%), chloramphenicol (84\%), rifampicin (88\%), LNZ (97\%), vancomycin (99\%).

Gram negative pathogens continue to cause the most severe infections in burn patients. Morovat et al. reports that P. aeruginosa (44\%) followed by MRSA (33\%) is the most common organism isolated in burn centers in US. ${ }^{21}$ But according to our study P. aeruginosa followed by
Klebsiella pneumonia followed by Staphylococcus aureus and MRSA is the commonest organisms isolated in our centre.

Various studies shows that pseudomonas is resistant to piperacillin (65.8\%), imipinem (62\%), ciprofloxacin $(60.25 \%)$, gentamicin $(63 \%)$ and ceftazidime $(65 \%) .22-27$ In our study over all resistance to piperacillin (77.3\%), IPM $(25 \%)$, ciprofloxacin $(51 \%)$, gentamicin $(63.2 \%)$ and ceftazidime (95\%). But as observed and compared over a period of these four years there is increased resistance to carbepenem group of drugs, in 2011 sensitivity is $85 \%$ which reduced to $59.1 \%$ in 2014 . As time goes on there is increased sensitivity to polymyxin group of drugs (colisitin-89.7\%) $(\mathrm{p}=0.000)$ and other gram negative organism $(85 \%)(\mathrm{p}=0.000)($ Figure 1,2$)$.

Klebsiella, E. coli, Proteus and Acinetobacter do not show significant difference in resistance pattern to carbepenem group and also showed increasing sensitivity to the polymyxin group of drugs.

The causes for increase in drug resistance might be misuse, cross contamination, change in genome of the organisms or premature change of antibiotics. In our centre we send the swabs at regular intervals to prevent misuse of antibiotics and premature change of antibiotics. In a study by Weber et al. showed that the rate of crosscolonization with resistant organisms in 66 critically ill children with severe burns and inhalation injury on ventilator support during a 5 year period was extremely low (3.2 cases per 1000 patient-days) in such a center where housing burn patients in individual nursing units composed of individual isolation rooms, each with its own laminar airflow and should allow all intensive and burn care procedures, including ventilation and operative procedures, to be done within the burn centre itself, or, as a minimum, the facility design should minimize the need to transfer patients out of the burn unit for different aspects of their care. ${ }^{28}$

\section{CONCLUSION}

An effective infection control policy is very much required to reduce or eliminate endemic pathogenic and/or antibiotic resistant organisms, prevent the establishment of antibiotic-resistant organisms as the predominant nosocomial flora of the burn unit, and prevent cross-contamination. ${ }^{29}$

In developing countries like India cross contamination with resistance microbial flora cannot be prevented because of overcrowding, inadequate sterilization and disinfection practices, gross contamination of the environment, lack of isolation facilities, inadequate hand washing and inadequate resources which are main culprits of cross contamination and increased resistance to higher antibiotics. For effective prevention of developing resistance to higher antibiotics the burn centres should look in and bring a strict antibiotic policy. 
Funding: No funding sources

Conflict of interest: None declared

Ethical approval: The study was approved by the institutional ethics committee

\section{REFERENCES}

1. Travis J. Reviving the antibiotic miracle? Science. 1994;264:360-2.

2. Levy SB. Factors impacting on the problem of antibiotic resistance. J Antimicrob Chemother. 2002;49:25-30.

3. Taneja N, Emmanuel R, Chari PS, Sharma M. A prospectivestudy of hospital-acquired infections in burn patients at a tertiary care referral centre in north India. Burns. 2004;30:665-9

4. Ekrami A, Kalanter E. Bacterial infections in burn patients at a burn hospital in Iran. Indian J Med Res. 2007;126:541-4.

5. Revathi G, Puri J, Jain BK. Bacteriology of burns. Burns. 1998;24:347-9.

6. Altoparlak U, Erol S, Akcay MN, Celebi F, Kadanali A. The time-related changes of antimicrobial resistance patterns and predominant bacterial profiles of burn wounds and body flora of burned patients. Burns. 2004;30:660-4.

7. Mathur P, Kapil A, Das B. Nosocomial bacteraemia in intensive care unit patients of a tertiary care centre. Indian J Med Res. 2005;122:305-8.

8. Mathai E. Nosocomial bacteraemia and antimicrobial resistance in intensive care units. Indian J Med Res. 2005;122:285-7.

9. NNIS. National Nosocomial Infections Surveillance (NNIS) system report, data summary from October 1986-April 1998. Am J Infect Control. 1998;26:52233.

10. Hutchison ML, Govan JR. Pathogenicity of microbes associated with cystic fibrosis. Microbes Infect. 1999;1:1005-14.

11. Tummler B, Kiewitz C. Cystic fibrosis: an inherited susceptibility to bacterial respiratory infections. Mol Med Today. 1999;5:351-8.

12. Bergogne-Berezin E, Towner KJ. Acinetobacter spp. as nosocomial pathogens: microbiological, clinical, and epidemiological features. Clin Microbiol Rev. 1996;9:148-65.

13. Bouza E, Cercenado E. Klebsiella and Enterobacter: antibiotic resistance and treatment implications. Semin Respir Infect. 2002;17:215-30.

14. 14. Hsueh PR, Teng LJ, Yang PC, Chen YC, Ho SW, Luh KT. Persistence of a multidrug resistant Pseudomonas aeruginosa clone in an intensive care burn unit. J Clin Microbiol. 1998;36:1347-51.

15. Mouton JW, den Hollander JG, Horrevorts AM. Emergence of antibiotic resistance amongst Pseudomonas aeruginosa isolates from patients with cystic fibrosis. J Antimicrob Chemother. 1993;31:919-26.
16. Krcmery V, Trupl J. Nosocomial outbreak of meropenem resistant Pseudomonas aeruginosa infections in a cancer centre. J Hosp Infect. 1994;26:69-71.

17. Armstrong D, Neu H, Peterson LR, Tomasz A. The prospects of treatment failure in the chemotherapy of infectious diseases in the 1990s. Microb Drug Resist. 1995;1:1-4.

18. Jones RN. Resistance patterns among nosocomial pathogens: trends over the past few years. Chest. 2001;119:397S-404S.

19. Livermore DM. Multiple mechanisms of antimicrobial resistance in Pseudomonas aeruginosa: our worst nightmare? Clin Infect Dis. 2002;34:634-40.

20. Schmitz F-J, Krey A, Geisel R, Verhoef J, Heinz HP, Fluit AC. Susceptibility of 302 methicillinresistant Staphylococcus aureus isolates from 20 European university hospitals to vancomycin and alternative antistaphylococcal compounds. SENTRY Participants Group. Eur J Clin Microbiol Infect Dis. 1999;18:528-30.

21. Morovat T, Badrosadat K, Mohammad E, NamamAli A. Increased of resistance to antibiotics among bacteria isolated from burn wounds. Rev Epidemiol Control Infect. 2013;3(2):38-9.

22. Bayram Y, Parlak M, Aypak C, Bayram I. Threeyear review of bacteriological profile and antibiogram of burn wound isolates in Van, Turkey. Int J Med Sci. 2013;10(1):19-23.

23. Branski LK, Al-Mousawi A, Rivero H, Jeschke MG, Sanford AP, Herndon DN. Emerging infections in burns. Surg Infect (Larchmt). 2009;10(5):389-97.

24. Rezaei E, Safari H, Naderinasab M, Aliakbarian H. Common pathogens in burnwound and changes in their drug sensitivity. Burns. 2011;37(5):805-7.

25. Jabalameli F, Mirsalehian A, Khoramian B, Aligholi M, Khoramrooz SS, Asadollahi P, et al. Evaluation of biofilm production and characterization of genes encoding type III secretionsystem among Pseudomonas aeruginosa isolated from burn patients. Burns. 2012;38(8):1192-7.

26. Qader AR, Muhamad JA. Nosocomial infection in Sulaimani burn hospital, Iraq. Ann Burns Fire Disasters. 2010;23(4):177-81.

27. Sun FJ, Zhang XB, Fang Y, Chen J, Xing H, Shi H, et al. Spectrum and drug resistance of pathogens from patients with burns. Burns. 2012;38(8):112430.

28. Weber JM, Sheridan RL, Schulz JT, Tompkins RG, Ryan CM. Effectiveness of bacteria-controlled nursing units in preventing cross-colonization with resistant bacteria in severely burned children. Infect Control Hosp Epidemiol. 2002;23:549-51.

29. Weber J, McManus A. Infection control in burn patients. Burns, 2004;30:A16-24.

Cite this article as: Lunawat A, Sharma R, Kolla V, Patel S. Emerging resistance of higher antimicrobials and growing sensitivity of old antimicrobials against existing infections in burns. Int Surg J 2015;2:385-91. 